\title{
R-Silsesquioxane-Based Network Polymers by Fluoride Catalyzed Synthesis: An Investigation of Cross-Linker Structure and Its Influence on Porosity
}

\author{
Nai-hsuan Hu (D) and Joseph C. Furgal *D \\ Department of Chemistry and Center for Photochemical Sciences, Bowling Green State University, \\ Bowling Green, OH 43403, USA; naihsuh@bgsu.edu \\ * Correspondence: furgalj@bgsu.edu
}

Received: 3 April 2020; Accepted: 13 April 2020; Published: 15 April 2020

\begin{abstract}
Silsesquioxane-based networks are an important class of materials that have many applications where high thermal/oxidative stability and porosity are needed simultaneously. However, there is a great desire to be able to design these materials for specialized applications in environmental remediation and medicine. To do so requires a simple synthesis method to make materials with expanded functionalities. In this article, we explore the synthesis of R-silsesquioxane-based porous networks by fluoride catalysis containing methyl, phenyl and vinyl corners ( $\left.\mathrm{R}-\mathrm{Si}(\mathrm{OEt})_{3}\right)$ combined with four different bis-triethoxysilyl cross-linkers (ethyl, ethylene, acetylene and hexyl). Synthesized materials were then analyzed for their porosity, surface area, thermal stability and general structure. We found that when a specified cage corner (i.e., methyl) is compared across all cross-linkers in two different solvent systems (dichloromethane and acetonitrile), pore size distributions are consistent with cross-linker length, pore sizes tended to be larger and $\pi$-bond-containing cross-linkers reduced overall microporosity. Changing to larger cage corners for each of the cross-linkers tended to show decreases in overall surface area, except when both corners and cross-linkers contained $\pi$-bonds. These studies will enable further understanding of post-synthesis modifiable silsesquioxane networks.
\end{abstract}

Keywords: silsesquioxanes; sol-gel; network polymers; porosity; fluoride catalysis; POSS; aerogels; alkoxysilanes

\section{Introduction}

Sol-gel reactions of R- and bis-R-alkoxysilanes have been used over the years to synthesize a wide variety of highly porous materials containing hybrid inorganic/organic moieties [1-6]. Although historically these types of porous materials have focused on using bridged alkoxysilanes synthesized by acid or base catalysis in a random structural formation, there are many advances in controlling the reactivity that give more focused pore sizes and overall reaction control [7-14]. There have been a few strategies implemented for this, including extensive processing and templation methodologies to maximize porosity and pore-structure stability [10,12,15-21]. The advancements and mechanistic understanding of fluoride catalysis (non-stoichiometric) as a technique to synthesize these types of structures has enabled vast improvements in these materials from a structural and synthetic control standpoint [22,23]. For example, Corma et al. have found good synthetic control with fluoride catalysis methods and showing bridging moiety control of porosity [23]. These improvements are due to the rapid equilibration processes that occur, which allow for the facile generation of more uniform porosity in materials as well as controlled swellability [13,15,24-29].

Recently, we reported on the tetrabutylammonium fluoride-(TBAF) catalyzed synthesis of methyl-silsesquioxane-based ethane bridged network materials, where we explored the importance 
of reaction solvent and water content in modifying the overall pore size distributions of a single cross-linker system [29]. Though many reports speculate that the pore sizes obtained in sol-gel reactions are directly related to the bridging groups used, especially for rigid spacers [2,26,30-32], we found that multiple pore size distributions $(0.5$ to $100 \mathrm{~nm})$ could be obtained by simply changing the reaction solvent for the same bridge. For example, dichloromethane (DCM) favored micropores on the order of $1.2 \mathrm{~nm}$ and gel particles, while changing the reaction solvent to acetonitrile (ACN) gave pores centered around $3 \mathrm{~nm}$ and favored global gelation of the entire system. All the synthesized materials favored non-polar solvents as expected for organogels based on networked silsesquioxanes.

Though high porosity materials with static or non-functionalizable pores are useful in many applications [33-36], it is often desirable to impart additional functionality to these materials for many specialized uses. such as in biology or environmental remediation. as capture and release agents $[2,17,37-39]$. These functionalities may include hydrophilic groups, amino-acids and reversible chemistries such as "click" or complexation ligands [40-44]. Many researchers have been working on methods to synthesize active silsesquioxane-based networks, albeit primarily through preformed cage methods. In terms of preformed cage systems, Ervithayasuporn et al. have developed a recyclable methacrylate-POSS (polyhedral oligomeric silsesquioxanes) porous network which can efficiently bind $\mathrm{Pd}$ and acts as a catalyst for alcohol oxidation in the presence of water [45]. Shimojima et al. developed a photo-responsive azobenzene-based porous network using hydrosilylation chemistries [46], and Liu et al. have used Heck cross-coupling to synthesize porous POSS with surface areas up to $600 \mathrm{~m}^{2} \mathrm{~g}^{-1}$ and used them for water purification by removal of lead [17]. In regards to active in-situ-formed networks more similar to this work, Gan et al. have developed a series of luminescent networks materials using pyridinium-based cross-linkers [47], and Moreau et al. have synthesized a series of chiral-bridged porous materials that impart helical structure during the sol-gel process [12].

While the methods above describe the most desirable methods to incorporate specific functionalities before synthesis, there are often challenges with monomer purification or compatibility with the other components during synthesis (i.e., phase separation). Therefore, the incorporation of R-alkoxysilanes or bridging groups with the ability of post-synthesis modification is sought after and may include reactive systems such as ethylene, vinyl, alkynyl, phenyl, azido, amino or other substitutable groups $[27,38,48-51]$. One of the challenges with incorporating functionalizable R-substituents within the structure is that many of these components have large sizes, $\pi$-stacking or hydrogen bonding that can hinder the accessibility of pores to analytes or modification reactions. In this case, the choice of synthesis technique and/or post-synthesis-processing methods is very important to keep pores open for future reactions. An additional goal is to not only impart later functionalization, but to be able to control pore sizes to include or exclude different species of interest, something that is still difficult to achieve.

In this study we expand on our previous findings on the importance of solvent in controlling pore size distributions in ethyl-bridged methylsilsesquioxane networks. We apply our knowledge of those simple systems to determine how the incorporation of other silsesquioxane building blocks such as phenyl/vinyl-silyl corner groups and cross-linker length and rigidity affect the properties of fluoride-catalyst-synthesized post-synthesis modifiable porous networks.

\section{Materials and Methods}

Materials: Methyltriethoxysilane $\left(\mathrm{CH}_{3} \mathrm{Si}(\mathrm{OEt})_{3}, \quad \mathrm{MeSi}(\mathrm{OEt})_{3}\right)$, vinyltriethoxysilane $\left.\left(\mathrm{CH}_{2} \mathrm{CHSi}(\mathrm{OEt})_{3} \text {, vinylSi(OEt }\right)_{3}\right)$, phenyltriethoxy-silane $\left(\mathrm{C}_{6} \mathrm{H}_{5} \mathrm{Si}(\mathrm{OEt})_{3}, \quad \mathrm{PhSi}(\mathrm{OEt})_{3}\right), \quad$ 1,2bis(triethoxysilyl)ethane $\left((\mathrm{EtO})_{3} \mathrm{SiCH}_{2} \mathrm{CH}_{2} \mathrm{Si}(\mathrm{OEt})_{3}, \quad \mathrm{BTSE}\right), \quad$ 1,2-bis(triethoxysilyl)ethylene $\left((\mathrm{EtO})_{3} \mathrm{SiCHCHSi}(\mathrm{OEEt})_{3}, \mathrm{BTSEE}\right)$, 1,6-bis(triethoxysilyl)hexane $\left((\mathrm{EtO})_{3} \mathrm{Si}\left(\mathrm{CH}_{2}\right)_{6} \mathrm{Si}(\mathrm{OEt})_{3}, \mathrm{BTSH}\right)$ and 1,2-bis(triethoxysilyl)acetylene $\left((\mathrm{EtO})_{3} \mathrm{SiCCSi}(\mathrm{OEt})_{3}, \mathrm{BTSA}\right)$ were purchased from Gelest, Inc., Morrisville, Pennsylvania, PA, USA. Acetonitrile (ACN) and dichloromethane (DCM) were purchased from Millipore Inc. Saint Louis, Missouri, MO, USA. Tetrabutylammonium fluoride (TBAF, 1.0 M in 
THF) was purchased from Acros Organics, Morris Plains, New Jersey, NJ, USA. Other chemicals and reagents as noted in the text were used as received.

General condensation reactions: $6.25 \mathrm{mmol}$ R-Silsesquioxane-Based porous networks by fluoride catalysis containing methyl, phenyl and vinyl corners ( $\left.\mathrm{R}-\mathrm{Si}(\mathrm{OEt})_{3}\right), 1.75 \mathrm{mmol}$ of cross-linker, and $0.75 \mathrm{~mL} \mathrm{H}_{2} \mathrm{O}$ were mixed in a $500 \mathrm{~mL}$ round-bottom flask. The mixture was then stirred by a magnetic bar for $5 \mathrm{~min}$ with $200 \mathrm{~mL}$ of reagent grade acetonitrile (ACN) or dichloromethane (DCM) as solvent. Tetrabutylammonium fluoride (TBAF) was then added to the mixture as catalyst. After $24 \mathrm{~h}$ of reaction, the reaction mixture was filtered if precipitate was formed. Remaining gel in the filter was then rinsed by corresponding solvent to remove the catalyst. Reactions retained without precipitation (i.e., sol- or global gel) for $24 \mathrm{~h}$ were transferred to a $500 \mathrm{~mL}$ beaker, then the mixture was dried under ambient. Gels from both methods were dried under high vacuum for $24 \mathrm{~h}$, ground to powder by mortar and pestle, then dried again under high vacuum to ensure the absence of solvent. These reaction conditions were used for the general synthesis of all materials studied in this manuscript. Each sample was synthesized three times, with surface area and full characterization conducted on the 2nd samples for consistency.

Analytical methods: Fourier-transform infrared spectroscopy (FTIR). All of the spectra were obtained from Thermo Scientific Nicolet iS5 Fourier Transform Infrared Spectrometer (Waltham, Massachusetts, MA, USA). Grounded samples were placed directly onto a ZnSe crystal, then scanned from 4000 to $400 \mathrm{~cm}^{-1}$ for 32 scans with $0.121 \mathrm{~cm}^{-1}$ resolution. Attenuated total reflection (ATR) method was applied to the analysis.

Specific surface area (SSA) and porosity analyses: A Micromeritics 3FLEX surface and catalyst characterization analyzer (Micromeritics Inc., Norcross, GA, USA) was used to analyze the surface area and porosity of all samples [29,52]. Samples were degassed at room temperature for $2 \mathrm{~h}$ with an $\mathrm{N}_{2}$ flush. The surface area was calculated by Brunauer-Emmet-Teller (BET) method. Pore volume and pore size distributions were calculated by density functional theory (DFT) methods. The measurements were carried out at $-196{ }^{\circ} \mathrm{C}(77 \mathrm{~K})$ while collecting $\mathrm{N}_{2}$ adsorption and desorption isotherms. The samples were first evacuated to $0.0001 \mathrm{mmHg}$ then gradually dosed with $\mathrm{N}_{2}$ gas until reaching saturated pressure $(760 \mathrm{mmHg}) . \mathrm{P} / \mathrm{Po}$ of the first adsorption point were calculated as single point surface area. The samples were then gradually evacuated to $\mathrm{P} / \mathrm{Po}$ points as set up to obtain desorption graph. In this paper, the mesopore data were determined by the multipoint method using 20 data points with $0.050(\mathrm{p} / \mathrm{p} 0)$ relative pressure increment starting from a relative pressure $0.015(\mathrm{p} / \mathrm{p} 0)$. The data were calculated by DFT method to obtain pore size distributions. Absorption and desorption isotherms are given in supporting information for all samples (Figure S1).

Thermalgravimetric analysis (TGA): ceramic yields and $\mathrm{T}_{5 \%}$ were measured by a TGA-50 (TA Instruments, Inc., New Castle, DE, USA) instrument. Ground samples of 10-20 mg of material were put into an alumina pan. The sample was heated under air $(60 \mathrm{~mL} / \mathrm{min})$ from room temperature to $1000^{\circ} \mathrm{C}$ at a rate of $10^{\circ} \mathrm{C} / \mathrm{min}$.

Solid state nuclear magnetic resonance: solid state ${ }^{29} \mathrm{Si}$ NMR was measured by a Bruker Avance III NMR spectrometer (Bruker, Inc., Billerica, MA, USA). A multinuclear double resonance CP-MAS probe was tuned to $119.23 \mathrm{MHz}$ with a $4 \mathrm{~mm}$ top-loading rotor. Ground samples were measured for 256 scans with a 20 to $-160 \mathrm{ppm}$ spectral window and $7 \mathrm{~s}$ of decay time. Experiments were run with a tightly packed zirconia spinner and spin rate of $9 \mathrm{kHz}$.

\section{Results and Discussion}

Cross-linkers with various electron density, rigidity and length were reacted with $\mathrm{R}-\mathrm{Si}(\mathrm{OEt})_{3}$ to determine how they impact structure and properties such as surface area, porosity, reactivity and sol-gel reaction completion, where $\mathrm{R}=\mathrm{Me}$, phenyl, vinyl (Scheme 1). While these types of cross-linkers have been explored in great deal in the literature, combinations of these with various corners under reversible fluoride conditions are still underexplored. Sol-gel reaction efficiencies were measured by TGA, based on analysis of post-curing wt. $\%$ drops at $\sim 200{ }^{\circ} \mathrm{C}$. We compared three 
cross-linkers against BTSE systems: [29] bis-triethoxysilylhexane (BTSH), bis-triethoxysilylethene (BTSEE), and bis-triethoxysilylacetylene (BTSA). We used a ratio of 1:0.36 of R-Si(OEt) ${ }_{3}$ to cross-linker for our standard conditions, as they have been found to offer the highest surface areas and best overall reaction completion [29]. We looked at reactions in two solvents, one of moderate polarity and low water miscibility, DCM, and one of high polarity and water miscibility, ACN. These solvents were chosen because of results from previous BTSE studies, which gave different mechanisms of reactivity, whereby DCM leads to precipitated gel particles and $\mathrm{ACN}$ gives global gelation in water-rich systems. In most sol-gel type processes, post-curing is necessary to reach reaction completion. However, in these systems using either DCM or ACN no post-curing was done in order to better compare results across linkers. This decision was reinforced by a tendency for reaction completion to be generally quite high and we wanted to limit the oxidation of $\pi$-bonds. All materials when dried out gave a white or translucent appearance and were amorphous in structure. The FTIRs for all samples in this series are given in Figure S2.
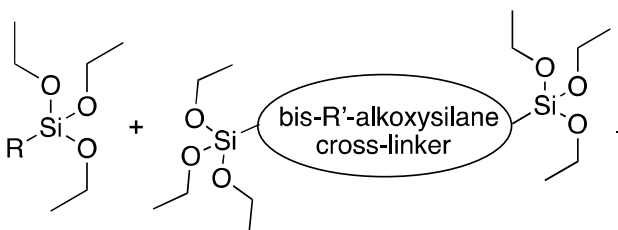
o-si cross-linker jo $R=$ methyl, phenyl
vinyl

$$
\begin{aligned}
& \text { R'= } \text { ethyl, } \\
& \text { ethylene, } \\
& \text { acetylene, } \\
& \text { hexyl }
\end{aligned}
$$

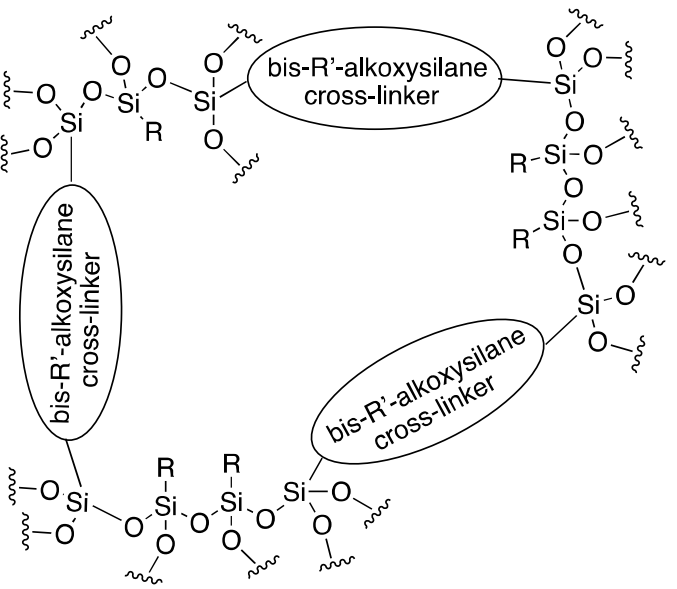

Scheme 1. Reaction to form silsesquioxane networks using fluoride-catalyzed synthesis. TBAF: tetrabutylammonium fluoride. ${ }^{*} \mathrm{RT}=$ room temperature.

\subsection{Cross-Linkers}

We started our study with methyl corner groups and exchanging out BTSE for each of the above cross-linkers (BTSEE, BTSA and BTSH) using standard conditions in DCM and ACN. We found that any of the above cross-linkers resulted in approximately half the surface area or less, regardless of solvent versus BTSE on its own (Table 1). Some of this decline can be attributed to low reaction completion efficiencies. Weight drops occurring below $200^{\circ} \mathrm{C}$ imply the presence of unreacted ethoxy/hydroxy groups in the structure. BTSEE and BTSA linkers both showed an especially prevalent drop of up to $15 \%$, which leads to lower ceramic yields than expected in the TGA for these samples (Figure 1). This is further confirmed by solid state ${ }^{29} \mathrm{Si}$ NMR (Figure 2 and Figure S3), which shows significant shoulders corresponding to ethoxy groups in both of these samples [53]. Solid state ${ }^{29} \mathrm{Si}$ NMR additionally shows that BTSEE and BTSA are effectively incorporated into the network by their distinctive positions at -82 and -111 ppm, respectively. In BTSH samples, the breadth of the solid state ${ }^{29} \mathrm{Si}$ NMR signal masks the cross-linkers and it cannot be deciphered from that of methyl-Si corner bonding. 
Table 1. Specific surface areas and thermalgravimetric analysis (TGA) decomposition and ceramic yield of materials from reactions with different cross-linkers in dichloromethane and acetonitrile.

\begin{tabular}{|c|c|c|c|c|c|}
\hline Cross-Linker & Solvent & $\begin{array}{l}\mathbf{P}=\text { Particle } \\
\mathbf{N}=\text { No Gel }\end{array}$ & $\begin{array}{l}\text { Surface Area } \\
\qquad\left(\mathrm{m}^{2} \mathrm{~g}^{-1}\right)\end{array}$ & $\begin{array}{c}\text { Temperature at } 5 \% \\
\text { Mass Loss }\left(T_{5 \%}\right)\end{array}$ & $\begin{array}{l}\text { Residue at } 1000^{\circ} \mathrm{C} \\
\text { (Ceramic Yield) }\end{array}$ \\
\hline \multicolumn{6}{|l|}{ BTSE } \\
\hline & DCM & $\mathrm{P}$ & 1076 & $361.3^{\circ} \mathrm{C}$ & $86.2 \%$ \\
\hline & $\mathrm{ACN}$ & $\mathrm{P}$ & 1022 & $451.6^{\circ} \mathrm{C}$ & $89.2 \%$ \\
\hline \multicolumn{6}{|l|}{ BTSEE } \\
\hline & DCM & $\mathrm{P}$ & 556 & $251.2^{\circ} \mathrm{C}$ & $83.1 \%$ \\
\hline & $\mathrm{ACN}$ & $\mathrm{P}$ & 423 & $183.4^{\circ} \mathrm{C}$ & $76.5 \%$ \\
\hline \multicolumn{6}{|l|}{ BTSA } \\
\hline & DCM & $\mathrm{P}$ & 454 & $214.7^{\circ} \mathrm{C}$ & $82.2 \%$ \\
\hline & $\mathrm{ACN}$ & $\mathrm{P}$ & 212 & $182.9^{\circ} \mathrm{C}$ & $77.7 \%$ \\
\hline \multicolumn{6}{|l|}{ BTSH } \\
\hline & DCM & $\mathrm{N}$ & 112 & $241.4^{\circ} \mathrm{C}$ & $64.6 \%$ \\
\hline & $\mathrm{ACN}$ & $\mathrm{N}$ & 414 & $239.2^{\circ} \mathrm{C}$ & $65.7 \%$ \\
\hline
\end{tabular}

BTSE: 1,2-bis(triethoxysilyl)ethane; BTSEE: 1,2-bis(triethoxysilyl)ethylene; BTSA: 1,2-bis(triethoxysilyl)acetylene; BTSH: 1,6-bis(triethoxysilyl)hexane; DCM: dichloromethane; ACN: acetonitrile.
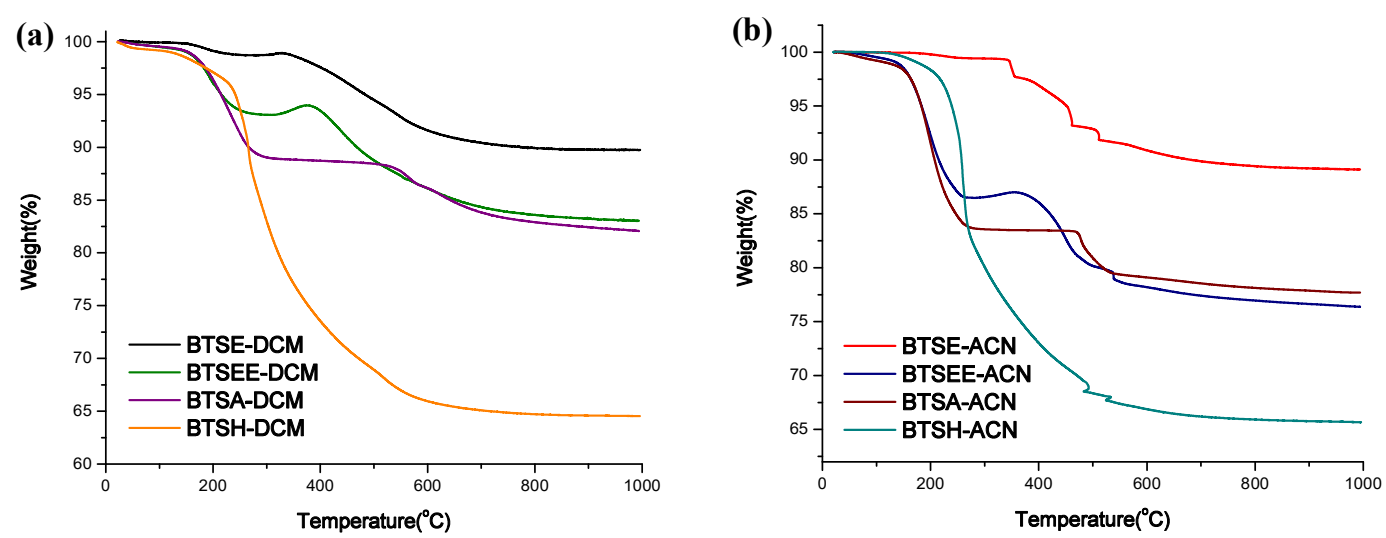

Figure 1. Thermal Gravimetric Analysis (TGA) graphs (in air) of materials from reactions with different cross-linkers in (a) dichloromethane and (b) acetonitrile, note BTSEE shows oxidation of the double bond at $400{ }^{\circ} \mathrm{C}$.

(a)

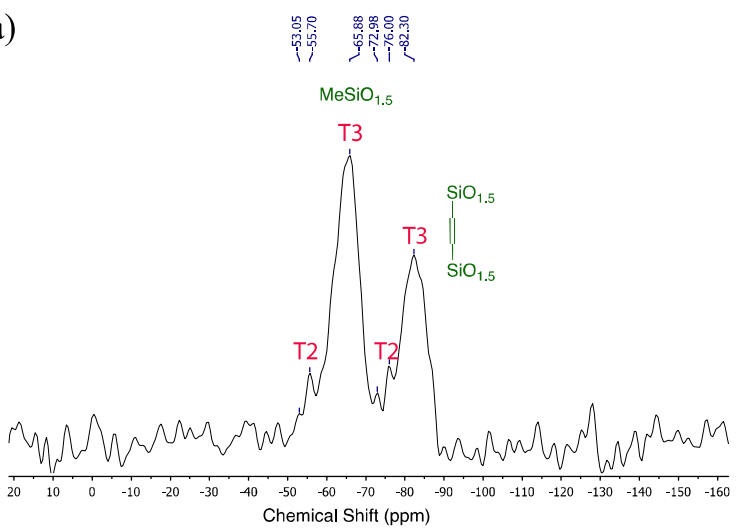

(b)

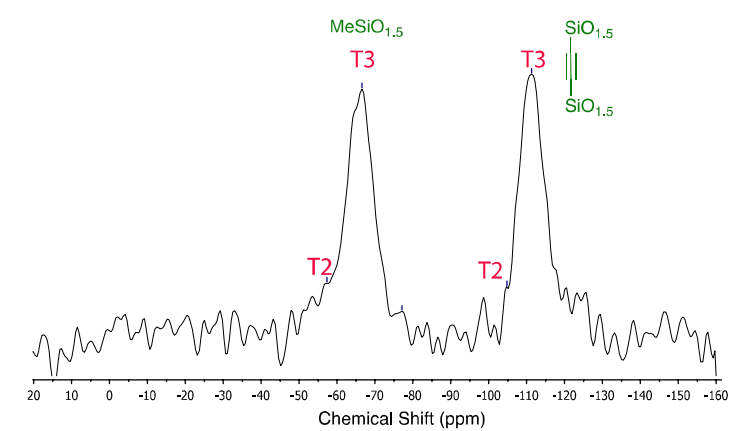

Figure 2. Solid state ${ }^{29}$ Si nuclear magnetic resonance (NMR) of (a) Me-BTSEE-based network polymer from DCM showing unreacted ethoxy shoulders $\left(\mathrm{T}_{2}\right)$ at -55 and $-76 \mathrm{ppm}$ and main peak for $\mathrm{T}_{3}$ at -65 and -85 , respectively, (b) Me-BTSA-based network polymer from DCM showing unreacted ethoxy shoulders $\left(T_{2}\right)$ at -67 and -104 ppm and main peak for $T_{3}$ at -66 and -111 , respectively. 
Reactions with cross-linkers BTSEE and BTSA in DCM show precipitation within $1 \mathrm{~h}$ of adding catalyst to the reaction, with specific surface area (SSA) trending similarly with values of 556 and $454 \mathrm{~m}^{2} \mathrm{~g}^{-1}$. This decline in SSA for BTSEE and BTSA can most likely be attributed to difficulties in the system reaching reaction completion. Incomplete networks contain large amounts of pore-blocking ethoxy/hydroxy groups. This is evidenced by "post-curing" drops in the TGA below $200{ }^{\circ} \mathrm{C}$ (Figure 1a). For example, with BTSA and BTSEE, though pore size distribution patterns are similar to reactions with BTSE, they show $10 \%$ and $7 \%$ drops in this "post-curing" region of the TGA, which result in a loss of $\sim 0.2 \mathrm{~cm}^{3} / \mathrm{g}$ of cumulative pore volume, equivalent to half the BTSE SSA. In addition, materials with BTSEE in both solvents show oxidation peaks at around $375^{\circ} \mathrm{C}$, this indicates that the ethylene $\pi$-bonds remain chemically active for further functionalization $[54,55]$.

In contrast, BTSH shows a significant drop-off in SSA in DCM to $112 \mathrm{~m}^{2} \mathrm{~g}^{-1}$ (Table 1), which is most likely attributed to a significant increase in pore size distribution and the increased flexibility and length of the linker. BTSH is also the only DCM sample to exhibit extensive hysteresis between adsorption and desorption isotherms in BET analysis, suggesting difficulty in removing $\mathrm{N}_{2}$ (Figure $\mathrm{S} 1$ ). Other samples show very little hysteresis. For reactions with BTSH, precipitation was not observed within $24 \mathrm{~h}$ and the reaction mixture was air-dried in a beaker resulting in global gelation occurring during the drying process. The flexibility of this linker gives a higher solubility for intermediates, but also a higher propensity for pore collapse [56]. This leads to lower surface areas being obtained when compared to the more rigid BTSEE and BTSA linkers.

In ACN samples there is a significant trend toward decreasing surface areas with increasing rigidity and electron density of the cross-linker (Table 1, Figure 1b). This difference between DCM and ACN is most likely attributed to the solubility variations of intermediate fragments during synthesis [29]. Going from BTSE to BTSEE to BTSA shows a narrowing of pore size distributions, but a trend towards mesopores versus DCM samples. Reactions with BTSA only show half the surface area $\left(212 \mathrm{~m}^{2} \mathrm{~g}^{-1}\right)$ compared with BTSEE $\left(423 \mathrm{~m}^{2} \mathrm{~g}^{-1}\right)$. This suggests reactions with these two different linkers have distinctive equilibration methods in forming intermediate structures and thus result in dissimilar pore size distributions. All samples synthesized in ACN show primarily type II-hysteresis loops that suggest a rigid structure of xerogels, and some difficulty in gas removal (Figure S1). Reactions with BTSH in ACN also show no precipitation within $24 \mathrm{~h}$ and are held in solution until concentrated. These materials resulted in pore size distributions more closely resembling BTSE in ACN. This contrasts many studies on the influence of cross-linker length on pore size in bis-alkoxysilyl-R systems, which suggest that increasing cross-linker length increases pore size, however rigidity and catalyst also play a role [56]. This effect will be the topic of future investigation.

There is considerable difference in the pore size distributions between DCM and ACN solvent systems. For all samples except for BTSH, the DCM solvent system results in overall smaller pores than that for the can-based reactions (Figure 3). This is expected based on previous studies and shows the importance of solvent choice when making silsesquioxane networks. The lower reaction efficiency of the shorter, more rigid cross-linkers is most likely due to steric hindrance from the growing partial cages nearby. This is more significant for the shortest spacer (BTSA) than even for BTSEE. One of the interesting anomalies is that the pore distribution for the BTSEE and BTSA samples in ACN show little microporosity in the distribution compared with BTSE-based materials, and their current studies in DCM; instead they contain mostly mesopores. It would be expected that these shorter and more rigid cross-linkers would be less influenced by solvent effects, but it appears that there must be a strong interaction between $\mathrm{ACN}$ and the cross-linkers, in which ACN could be associating itself with the cross-linker $\pi$-bonds and influencing the pore structure. Alternatively, there could be enough unreacted ethoxy/hydroxy groups in the structure to increase the pore sizes which would also correlate with the decreased SSA as previously mentioned. This would conflict with the FTIR analysis where there does not appear to be an abundance of hydroxy groups. 

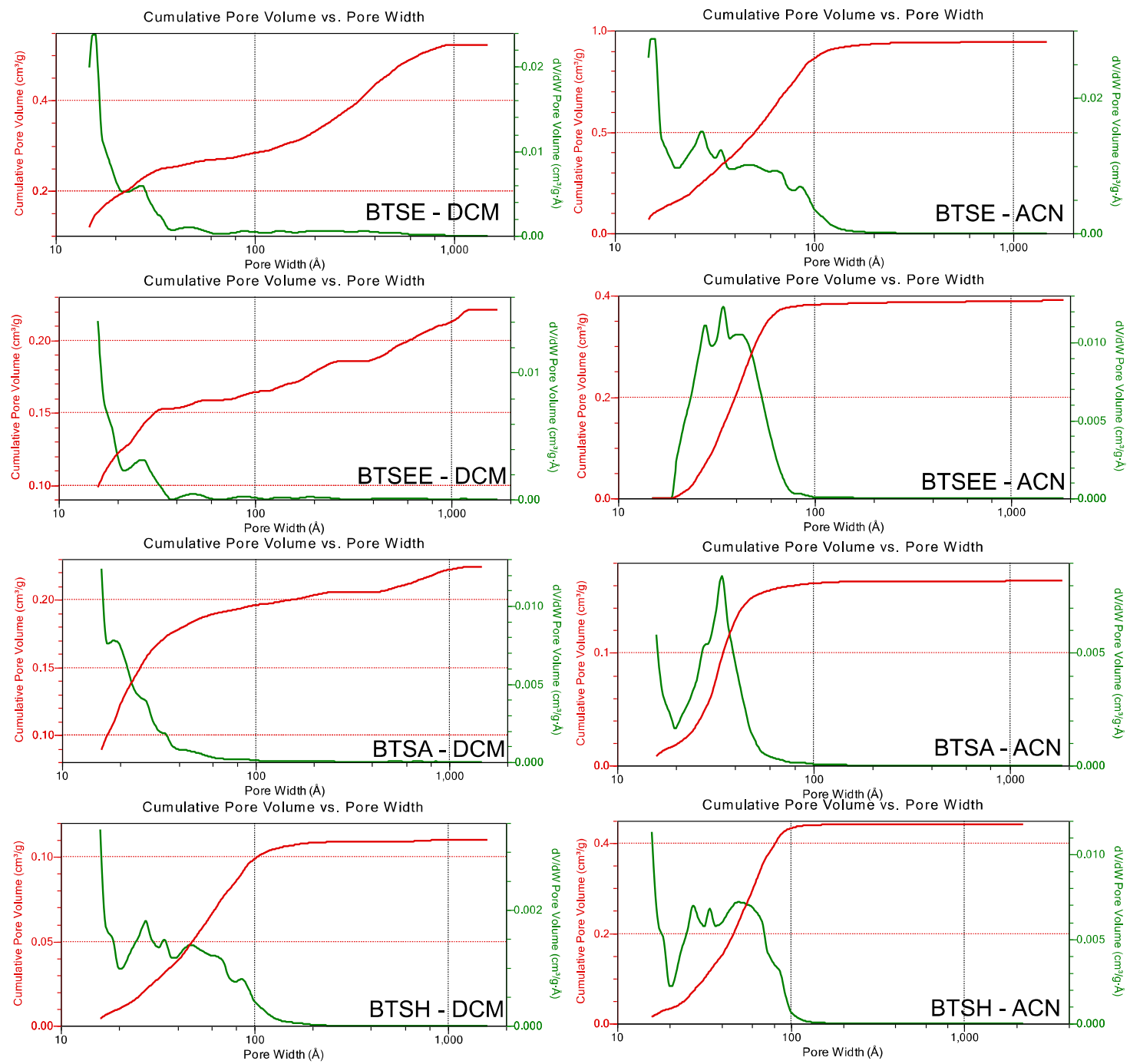

Figure 3. Density functional theory (DFT) method pore size distributions and cumulative pore volume from Brunauer-Emmet-Teller (BET) method measurement for Me-BTSE, Me-BTSEE, Me-BTSA and Me-BTSH in both DCM and ACN.

\subsection{Corner-Groups}

In addition to the above study comparing different cross-linkers and their influence on porosity, we were interested in changing out the methyl-based silsesquioxane corners for two other common R-groups, which could be further functionalized by post-synthesis modification. These groups have the potential for different steric, electronic and polarity interactions [57]. Though the use of methyl $\mathrm{R}$-groups is very attractive and should theoretically maximize the porosity in these systems, phenyl and vinyl R-group replacements were explored and their influence on structure-property relationships in DCM were determined to make a clear comparison based only on functional groups. As expected, we observed significant reductions in the ceramic yield and surface area when switching to larger spatially consuming R-groups (Table 2, Figure 4). The decrease in SSA is most likely due to decreasing pore accessibility. Note that all reactions with BTSH cross-linkers show good conversions in the sol-gel process by lack of mass loss at $\sim 200{ }^{\circ} \mathrm{C}$, but show the lowest overall thermal stability with decomposition starting to take place at $\sim 300{ }^{\circ} \mathrm{C}$ (in air). It is also interesting that BTSH networks did not form gel particles upon reaction in any experiments before concentration. Once the other cross-linker systems have been "post-cured" in TGA to remove residual ethoxy/hydroxy groups they show thermal stabilities of $\sim 400^{\circ} \mathrm{C}$. The FTIR for all samples in this series are given in Figure S4. 
Table 2. Surface areas of materials from reactions with different corner-silanes and cross-linkers in DCM.

\begin{tabular}{|c|c|c|c|c|c|}
\hline Cross-Linker & Corner Silane & $\begin{array}{l}P=\text { Particle } \\
\text { N }=\text { No Gel }\end{array}$ & $\begin{array}{l}\text { Surface Area } \\
\left(\mathrm{m}^{2} \mathrm{~g}^{-1}\right)\end{array}$ & $\begin{array}{c}\text { Temperature at } 5 \% \\
\text { Mass Loss }\left(T_{5 \%}\right)\end{array}$ & $\begin{array}{l}\text { Residue at } 1000^{\circ} \mathrm{C} \\
\text { (Ceramic Yield) }\end{array}$ \\
\hline \multicolumn{6}{|l|}{ BTSE } \\
\hline & $\begin{array}{l}\mathrm{MeSi}(\mathrm{OEt})_{3} \\
\text { (methyl) }\end{array}$ & $\mathrm{P}$ & 1076 & $483.7^{\circ} \mathrm{C}$ & $89.7 \%$ \\
\hline & $\begin{array}{c}\mathrm{PhSi}(\mathrm{OEt})_{3} \\
\text { (phenyl) }\end{array}$ & $\mathrm{P}$ & 1 & $278.9^{\circ} \mathrm{C}$ & $54.6 \%$ \\
\hline & $\begin{array}{l}\text { VinylSi }(\mathrm{OEt})_{3} \\
\quad(\text { vinyl) }\end{array}$ & $\mathrm{P}$ & 553 & $315.2^{\circ} \mathrm{C}$ & $77.5 \%$ \\
\hline \multicolumn{6}{|l|}{ BTSEE } \\
\hline & $\mathrm{MeSi}(\mathrm{OEt})_{3}$ & $\mathrm{P}$ & 556 & $229.1{ }^{\circ} \mathrm{C}$ & $83.1 \%$ \\
\hline & $\mathrm{PhSi}(\mathrm{OEt})_{3}$ & $\mathrm{P}$ & 245 & $216.8^{\circ} \mathrm{C}$ & $57.8 \%$ \\
\hline & VinylSi(OEt) ${ }_{3}$ & $\mathrm{P}$ & 455 & $369.3^{\circ} \mathrm{C}$ & $78.0 \%$ \\
\hline \multicolumn{6}{|l|}{ BTSA } \\
\hline & $\mathrm{MeSi}(\mathrm{OEt})_{3}$ & $\mathrm{P}$ & 454 & $214.7^{\circ} \mathrm{C}$ & $82.2 \%$ \\
\hline & $\mathrm{PhSi}(\mathrm{OEt})_{3}$ & $\mathrm{P}$ & 316 & $205.7^{\circ} \mathrm{C}$ & $64.0 \%$ \\
\hline & VinylSi(OEt $_{3}$ & $\mathrm{P}$ & 492 & $225.0^{\circ} \mathrm{C}$ & $78.5 \%$ \\
\hline \multicolumn{6}{|l|}{ BTSH } \\
\hline & $\mathrm{MeSi}(\mathrm{OEt})_{3}$ & $\mathrm{~N}$ & 112 & $241.4^{\circ} \mathrm{C}$ & $64.6 \%$ \\
\hline & $\mathrm{PhSi}(\mathrm{OEt})_{3}$ & $\mathrm{~N}$ & - & $213.5^{\circ} \mathrm{C}$ & $31.1 \%$ \\
\hline & VinylSi $(\mathrm{OEt})_{3}$ & $\mathrm{~N}$ & - & $242.0^{\circ} \mathrm{C}$ & $62.4 \%$ \\
\hline
\end{tabular}

(a)
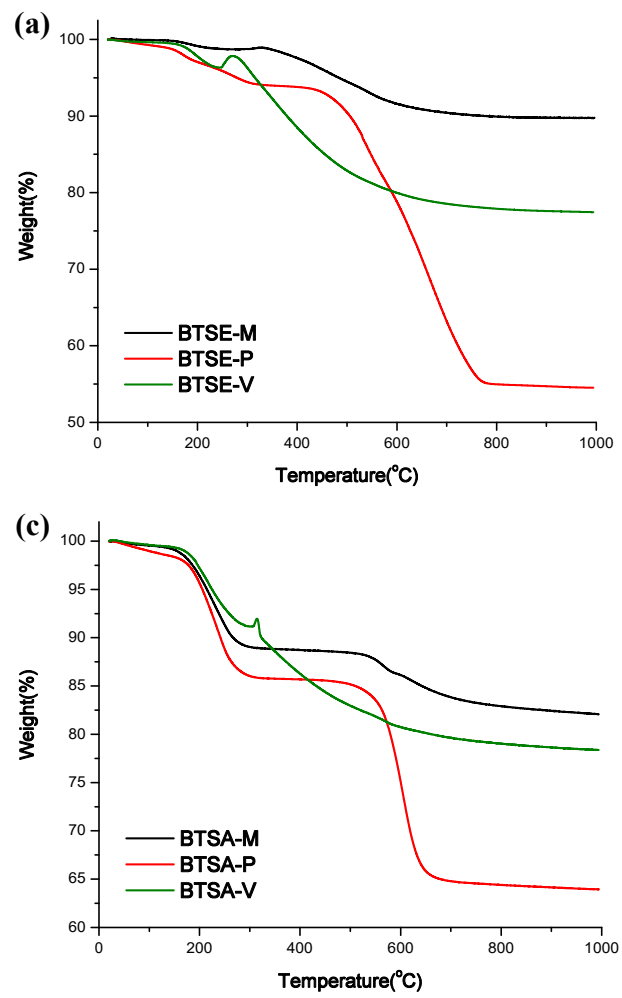

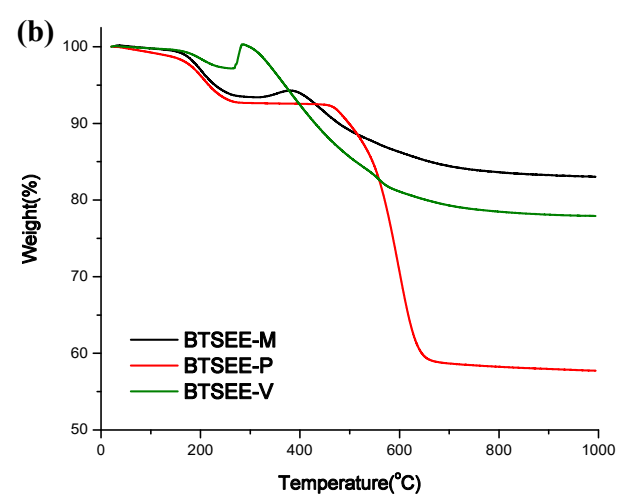

(d)

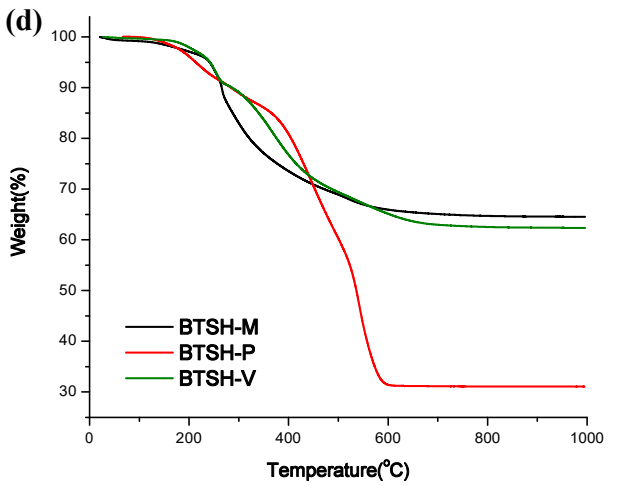

Figure 4. TGA graphs of materials from reactions with three corner-silanes and (a) BTSE, (b) BTSEE, (c) BTSA, (d) BTSH from DCM. BTSE: 1,2-bis(triethoxysilyl)ethane; BTSEE: 1,2-bis(triethoxysilyl)ethylene; BTSA: 1,2-bis(triethoxysilyl)acetylene; BTSH: 1,6-bis(triethoxysilyl)hexane; DCM: dichloromethane; ACN: acetonitrile.

Reactions with phenyl corners tend to give the best network formation with BTSEE and BTSA. These have substantially more cumulative pore volume $\left(>0.2 \mathrm{~cm}^{3} \mathrm{~g}^{-1}\right)$ and SSA than their BTSE and BTSH counterparts $\left(\sim 0 \mathrm{~m}^{2} \mathrm{~g}^{-1} \mathrm{SSA}\right)$, which seem to react poorly or have extensive pore collapse, and have cumulative pore volumes less than $0.001 \mathrm{~cm}^{3} \mathrm{~g}^{-1}$ (Table 2 and Figure S5). Furthermore, reactions with BTSEE and BTSA tend to favor microporosity versus BTSE and BTSH, which favor 
mesoporosity, albeit all systems are relatively disperse in porosity. The reasoning for this distinction likely lies in the ability for $\pi$-bond overlap between the BTSEE and BTSA cross-linkers with the phenyl corners, which can enable an almost templated alignment for reactions to occur. The lower cumulative pore volume of the BTSA $\left(0.2 \mathrm{~cm}^{3} \mathrm{~g}^{-1}\right)$ systems correspond closely to the $\sim 15 \%$ drop in the TGA curve from incomplete reactions. So even with the possibility of $\pi$-bond overlap selectively enabling smaller pore sizes, they do little to aid in reaction completion [58]. An alternative explanation for this phenomenon would be based on cross-linker rigidity, which was discussed in great detail by Shea and Loy [26], as well as Corma et al. [23]. BTSA and BTSEE offer far more rigidity than those of BTSE and BTSH and by locking the system together more tightly the pores become more accessible in the cross-linkers with $\pi$-bonds. This theory is supported by the SSA's found for each system, with BTSE and BTSH offering no surface area (i.e., non-accessible pores), while both BTSA and BTSEE are above $200 \mathrm{~m}^{2} \mathrm{~g}^{-1}$.

Networked materials with vinyl groups on the corners tend to show similar trends to that as phenyl, but are less hindering to overall sol-gel reaction efficiency as evidenced by TGA (Figure 4) and SSA in Table 2. Vinyl groups from vinylSi $(\mathrm{OEt})_{3}$ stay chemically active in the material and show a slight oxidation peak at around $300^{\circ} \mathrm{C}$ with BTSE, BTSEE and BTSA. This is due to the reactivity of the vinyl groups when heated in the presence of oxygen [49,50]. For each of the vinyl corners, except for reactions with BTSH, there was SSA of 455,492 and $553 \mathrm{~m}^{2} \mathrm{~g}^{-1}$ respectively for BTSA, BTSEE and BTSE, which are too similar to make major inferences about them. While for BTSE the SSA is about half that for methyl, the good compatibility and higher rigidity of BTSA and BTSEE samples with vinyl offer very similar surface areas to their methyl counterparts and in the case of BTSA, it is slightly higher. In reactions with BTSA, BTSEE and BTSE, similar pore distributions are achieved, primarily in the micropore size domain, while those with BTSH have a very broad pore distribution spanning from $\sim 5$ to $>100 \mathrm{~nm}$ (Figure S5). Materials with BTSH and vinyl did not show any significant surface area.

One of the interesting effects of the addition of cross-linkers and corner groups that contain $\pi$-bonds is that their slight electron-withdrawing nature should allow more efficient attack of fluoride on silicon and thus make the reactions more dynamic in nature. Laine et al. have described multiple instances where addition of $\pi$-containing silsesquioxane systems enables better rearrangement of POSS cages $[59,60]$. So it is quite surprising that we see far less reaction completion for the $\pi$-bond-containing structures and as such sterics and rigidity of the components must have a stronger influence than electronics on the material formation.

\section{Conclusions}

We have found that cross-linker and corner monomer choice largely affect surface area, reaction completion efficiency and pore size distribution for fluoride-catalyzed network polymer formation. Rigid cross-linkers such as BTSEE or BTSA tend to decrease surface area in both DCM and ACN, and give a narrower pore size distribution in ACN than DCM. Longer and more flexible crosslinkers like BTSH cause products to remain in solution indefinitely and these reactions must be concentrated to dryness in order to get solid or gel precipitate, often leading to large pore distributions and low SSA. There is no evidence of a relevant trend in pore size distributions related to cross-linker lengths and rigidities, with BTSEE and BTSA giving overall larger pores than those observed for BTSE. This suggests that the addition of corner units complemented with cross-linkers alters the structure substantially over using cross-linkers alone. Reactions with exchanged corners from Me to Ph or vinyl tend to show significant decreases in surface area with BTSE and BTSH, however due to favorable interactions between the Ph and vinyl systems with $\pi$-containing cross-linkers (BTSEE and BTSA) these systems showed approximately the same or higher SSA relative to BTSE. These results further our understanding of fluoride-catalyzed silsesquioxane network formation studies and give increased evidence for the importance of solvent choice in determining material properties. In addition, we discovered that both vinyl groups in corner groups and $\pi$-bonds in BTSEE are still chemically active after polymerization. This insight offers the ability to incorporate reactive moieties as corner 
groups and cross-linkers. For example, amino acids or thiol ether groups can be incorporated in the material to improve hydrophilicity. This reaction methodology gives great potential of post-synthesis modifications for applications ranging from selective capture of environmental contaminants such as lead, phosphorous or oil, to separation materials for drugs and oil/water mixtures.

Supplementary Materials: The following are available online at http:/www.mdpi.com/1996-1944/13/8/1849/s1. Figure S1: (a) Isotherm graphs from reactions with different cross-linkers in dichloromethane (DCM) and acetonitrile (ACN), Plus (light red) = adsorption, circle (dark red = desorption). (b) Isotherm graphs of materials from reactions with different corner-silanes and cross-linkers, $\mathrm{P}=$ phenyl, $\mathrm{V}=$ vinyl, $\mathrm{M}=$ methyl from $\mathrm{DCM}$, Plus (light red) = adsorption, circle (dark red = desorption), Figure S2: IR spectra of materials from reactions with different cross-linkers in dichloromethane (DCM) and acetonitrile (ACN), Figure S3: ${ }^{29} \mathrm{Si}$ NMR of methyl silsesquioxane based network polymer with hexyl spacer made in DCM. Note there are not extensive shoulders or side peaks indicating near complete reaction, Figure S4: IR spectra of materials from reactions with different corner-silanes and cross-linkers, $\mathrm{P}=$ phenyl, $\mathrm{V}=$ vinyl, $\mathrm{M}=$ methyl from DCM, Figure S5. DFT pore size distribution plots and cumulative pore volume of materials from reactions with different corner-silanes and cross-linkers, $\mathrm{P}=$ phenyl, $\mathrm{V}=$ vinyl, $\mathrm{M}=$ methyl from $\mathrm{DCM}$.

Author Contributions: Conceptualization, N.-h.H. and J.C.F.; methodology, N.-h.H. and J.C.F.; software, N.-h.H.; validation, N.-h.H. and J.C.F.; formal analysis, N.-h.H.; investigation, N.-h.H.; resources, N.-h.H.; data curation, N.-h.H.; writing - original draft preparation, N.-h.H.; writing-review and editing, J.C.F.; visualization, N.-h.H. and J.C.F.; supervision, J.C.F.; project administration, J.C.F.; funding acquisition, J.C.F. All authors have read and agreed to the published version of the manuscript.

Funding: This research was funded by Bowling Green State University (BGSU) Startup Funding, as well as a Bowling Green State University Building Strength Grant.

Acknowledgments: The authors would like to thank BGSU for the startup funding and instrumentation support. We would also like to thank Chamika Lenora at BGSU for helpful discussions while putting this manuscript together and Cory Sims for helping with proofreading.

Conflicts of Interest: The authors declare no conflict of interest.

\section{References}

1. Brinker, C.J.; Scherer, G. Sol-Gel Science, 1st ed.; Academic Press, Inc.: Boston, MA, USA, 1991.

2. Mizoshita, N.; Tani, T.; Inagaki, S. Syntheses, properties and applications of periodic mesoporous organosilicas prepared from bridged organosilane precursors. Chem. Soc. Rev. 2011, 40, 789-800. [CrossRef] [PubMed]

3. Loy, D.A.; Shea, K.J. Bridged polysilsesquioxanes. highly porous hybrid organic-inorganic materials. Chem. Rev. 1995, 95, 1431-1442. [CrossRef]

4. Shea, K.J.; Loy, D.A. A mechanistic investigation of gelation. The sol-gel polymerization of precursors to bridged polysilsesquioxanes. Acc. Chem. Res. 2001, 34, 707-716. [CrossRef] [PubMed]

5. Schmidt, H.; Scholze, H.; Kaiser, A. Principles of hydrolysis and condensation reaction of alkoxysilanes. J. Non.-Cryst. Solids 1984, 63, 1-11. [CrossRef]

6. Croissant, J.G.; Cattoën, X.; Durand, J.O.; Chi Man, M.W.; Khashab, N.M. Organosilica hybrid nanomaterials with a high organic content: Syntheses and applications of silsesquioxanes. Nanoscale 2016, 8, 19945-19972. [CrossRef]

7. Li, Q.; Afeworki, M.; Callen, N.M.; Colby, R.J.; Gopinadhan, M.; Kochersperger, M.L.N.; Peterson, B.K.; Sansone, M.; Weston, S.C.; Calabro, D.C. Template-free self-assembly of mesoporous organosilicas. Chem. Mater. 2018, 30, 2218-2228. [CrossRef]

8. Barczak, M.; McDonagh, C.; Wencel, D. Micro- and nanostructured sol-gel-based materials for optical chemical sensing (2005-2015). Microchim. Acta 2016, 183, 2085-2109. [CrossRef]

9. Moreau, J.J.E.; Pichon, B.P.; Chi Man, M.W.; Bied, C.; Pritzkow, H.; Bantignies, J.L.; Dieudonné, P.; Sauvajol, J.L. A better understanding of the self-structuration of bridged silsesquioxanes. Angew. Chem. Int. Ed. 2003, 43, 203-206. [CrossRef]

10. Díaz-Morales, U.; Bellussi, G.; Carati, A.; Millini, R.; Parker, W.O.N.; Rizzo, C. Ethane-silica hybrid material with ordered hexagonal mesoporous structure. Microporous Mesoporous Mater. 2006, 87, 185-191. [CrossRef]

11. Boury, B.; Corriu, R.J.P.; Delord, P.; Le Strat, V. Structure of silica-based organic-inorganic hybrid xerogel. J. Non.-Cryst. Solids 2000, 265, 41-50. [CrossRef]

12. Moreau, J.J.E.; Vellutini, L.; Chi Man, M.W.; Bied, C. Shape-controlled bridged silsesquioxanes: Hollow tubes and spheres. Chem. A Eur. J. 2003, 9, 1594-1599. [CrossRef] [PubMed] 
13. Corriu, R.J.P. The control of nanostructured solids: A challenge for molecular chemistry. Eur. J. Inorg. Chem. 2001, 1109-1121. [CrossRef]

14. Pons, A.; Casas, L.; Estop, E.; Molins, E.; Harris, K.D.M.; Xu, M. A new route to aerogels: Monolithic silica cryogels. J. Non.-Cryst. Solids 2012, 358, 461-469. [CrossRef]

15. Boury, B.; Corriu, R.J.P.; Le Strat, V.; Delord, P. Generation of porosity in a hybrid organic-inorganic xerogel by chemical treatment. New J. Chem. 1999, 23, 531-538. [CrossRef]

16. Barton, T.J.; Bull, L.M.; Klemperer, W.G.; Loy, D.A.; McEnaney, B.; Misono, M.; Monson, P.A.; Pez, G.; Schere, G.W.; Vartuli, J.C.; et al. Tailored porous materials. Chem. Mater. 1999, 11, 2633-2656. [CrossRef]

17. Ge, M.; Liu, H. Fluorine-containing silsesquioxane-based hybrid porous polymers mediated by bases and their use in water remediation. Chem. A Eur. J. 2018, 24, 2224-2231. [CrossRef] [PubMed]

18. Kanamori, K. Monolithic silsesquioxane materials with well-defined pore structure. J. Mater. Res. 2014, 29, 2773-2786. [CrossRef]

19. Wang, S.; Tan, L.; Zhang, C.; Hussain, I.; Tan, B. Novel POSS-based organic-inorganic hybrid porous materials by low cost strategies. J. Mater. Chem. A 2015, 3, 6542-6548. [CrossRef]

20. Wu, Y.; Wang, D.; Li, L.; Yang, W.; Feng, S.; Liu, H. Hybrid porous polymers constructed from octavinylsilsesquioxane and benzene via Friedel-Crafts reaction: Tunable porosity, gas sorption, and postfunctionalization. J. Mater. Chem. A 2014, 2, 2160. [CrossRef]

21. Chaikittisilp, W.; Kubo, M.; Moteki, T.; Sugawara-Narutaki, A.; Shimojima, A.; Okubo, T. Porous siloxane-organic hybrid with ultrahigh surface area through simultaneous polymerization-destruction of functionalized cubic siloxane cages. J. Am. Chem. Soc. 2011, 133, 13832-13835. [CrossRef]

22. Cerveau, G.; Corriu, R.J.P.; Framery, E. Influence of the nature of the catalyst on the textural properties of organosilsesquioxane materials. Polyhedron 2000, 19, 307-313. [CrossRef]

23. Díaz, U.; García, T.; Velty, A.; Corma, A. Hybrid organic-inorganic catalytic porous materials synthesized at neutral $\mathrm{pH}$ in absence of structural directing agents. J. Mater. Chem. 2009, 19, 5970-5979. [CrossRef]

24. Burkett, C.M.; Edmiston, P.L. Highly swellable sol-gels prepared by chemical modification of silanol groups prior to drying. J. Non.-Cryst. Solids 2005, 351, 3174-3178. [CrossRef]

25. Burkett, C.M.; Underwood, L.A.; Volzer, R.S.; Baughman, J.A.; Edmiston, P.L. Organic-inorganic hybrid materials that rapidly swell in non-polar liquids: Nanoscale morphology and swelling mechanism. Chem. Mater. 2008, 20, 1312-1321. [CrossRef]

26. Shea, K.J.; Loy, D.A. Bridged polysilsesquioxanes. Molecular-engineered hybrid organic-inorganic materials. Chem. Mater. 2001, 13, 3306-3319. [CrossRef]

27. Furgal, J.C.; Yamane, H.; Odykirk, T.R.; Yi, E.; Chujo, Y.; Laine, R.M. High surface area, thermally stable, hydrophobic, microporous, rigid gels generated at ambient from $\mathrm{MeSi}(\mathrm{OEt})_{3} /(\mathrm{EtO})_{3} \mathrm{SiCH}_{2} \mathrm{CH}_{2} \mathrm{Si}(\mathrm{OEt})_{3}$ mixture by F-catalyzed hydrolysis. Chem. A Eur. J. 2018, 24, 274-280. [CrossRef] [PubMed]

28. Furgal, J.C.; Goodson, T., III; Laine, R.M. D $5 \mathrm{~h}\left[\mathrm{PhSiO}_{1.5}\right]_{10}$ synthesis via F- catalyzed rearrangement of [PhSiO 1.5] n. An experimental/computational analysis of likely reaction pathways. Dalt. Trans. 2016, 45, 1025-1039. [CrossRef]

29. Hu, N.; Lenora, C.U.; May, T.A.; Hershberger, N.C.; Furgal, J.C. In-situ formed methyl-co-(bis-R) silsesquioxane based polymer networks with solvent controlled pore size distributions and high surface areas. Mater. Chem. Front. 2020, 4, 851-861. [CrossRef]

30. Kuroda, K.; Shimojima, A.; Kawahara, K.; Wakabayashi, R.; Tamura, Y.; Asakura, Y.; Kitahara, M. Utilization of alkoxysilyl groups for the creation of structurally controlled siloxane-based nanomaterials. Chem. Mater. 2014, 26, 211-220. [CrossRef]

31. Loy, D.A.; Jamison, G.M.; Baugher, B.M.; Myers, S.A.; Assink, R.A.; Shea, K.J. Sol-gel synthesis of hybrid organic-inorganic materials. Hexylene- and phenylene-bridged polysiloxanes. Chem. Mater. 1996, 8, 656-663. [CrossRef]

32. Hu, L.C.; Shea, K.J. Organo-silica hybrid functional nanomaterials: How do organic bridging groups and silsesquioxane moieties work hand-in-hand? Chem. Soc. Rev. 2011, 40, 688-695. [CrossRef]

33. Singh, G.; Kim, I.Y.; Lakhi, K.S.; Srivastava, P.; Naidu, R.; Vinu, A. Single step synthesis of activated bio-carbons with a high surface area and their excellent $\mathrm{CO}_{2}$ adsorption capacity. Carbon 2017, 116, 448-455. [CrossRef] 
34. Long, H.; Harley-Trochimczyk, A.; Pham, T.; Tang, Z.; Shi, T.; Zettl, A.; Carraro, C.; Worsley, M.A.; Maboudian, R. High surface area $\mathrm{MoS}_{2}$ /graphene hybrid aerogel for ultrasensitive $\mathrm{NO}_{2}$ detection. Adv. Funct. Mater. 2016, 26, 5158-5165. [CrossRef]

35. Duan, L.; Zhou, Z.; Yao, B. Fabrication, structural characterization and uniaxial tensile properties of novel sintered multi-layerwire mesh porous plates. Materials 2018, 11, 156. [CrossRef]

36. Li, L.; Ma, X.; Chen, R.; Wang, C.; Lu, M. Nitrogen-containing functional groups-facilitated acetone adsorption by ZIF-8-derived porous carbon. Materials 2018, 11, 159. [CrossRef]

37. Fertier, L.; Théron, C.; Carcel, C.; Trens, P.; Wong Chi Man, M. PH-responsive bridged silsesquioxane. Chem. Mater. 2011, 23, 2100-2106. [CrossRef]

38. Randall, J.P.; Meador, M.A.B.; Jana, S.C. Polymer reinforced silica aerogels: Effects of dimethyldiethoxysilane and bis(trimethoxysilylpropyl)amine as silane precursors. J. Mater. Chem. A 2013, 1, 6642-6652. [CrossRef]

39. Guo, S.; Okubo, T.; Kuroda, K.; Shimojima, A. A photoresponsive azobenzene-bridged cubic silsesquioxane network. J. Sol-Gel Sci. Technol. 2016, 79, 262-269. [CrossRef]

40. Radi, B.; Wellard, R.M.; George, G.A. Controlled poly(ethylene glycol) network structures through silsesquioxane cross-links formed by sol-gel reactions. Macromolecules 2010, 43, 9957-9963. [CrossRef]

41. Yen, Y.C.; Ye, Y.S.; Cheng, C.C.; Lu, C.H.; Tsai, L.D.; Huang, J.M.; Chang, F.C. The effect of sulfonic acid groups within a polyhedral oligomeric silsesquioxane containing cross-linked proton exchange membrane. Polymer 2010, 51, 84-91. [CrossRef]

42. Jeon, J.H.; Lim, J.H.; Kim, K.M. Organic-inorganic hybrid nanocomposites of poly(sodium 4-styrenesulfonate) and octafunctional polyhedral oligomeric silsesquioxane (POSS). Macromol. Res. 2010, 18, 341-345. [CrossRef]

43. Li, Y.; Dong, X.-H.; Zou, Y.; Wang, Z.; Yue, K.; Huang, M.; Liu, H.; Feng, X.; Lin, Z.; Zhang, W.; et al. Polyhedral oligomeric silsesquioxane meets "click" chemistry: Rational design and facile preparation of functional hybrid materials. Polymer 2017, 125, 303-329. [CrossRef]

44. Kolb, H.C.; Finn, M.G.; Sharpless, K.B. Click chemistry: Diverse chemical function from a few good reactions. Angew. Chem. Int. Ed. 2001, 40, 2004-2021. [CrossRef]

45. Sangtrirutnugul, P.; Chaiprasert, T.; Hunsiri, W.; Jitjaroendee, T.; Songkhum, P.; Laohhasurayotin, K.; Osotchan, T.; Ervithayasuporn, V. Tunable porosity of cross-linked-polyhedral oligomeric silsesquioxane supports for palladium-catalyzed aerobic alcohol oxidation in water. ACS Appl. Mater. Interfaces 2017, 9, 12812-12822. [CrossRef] [PubMed]

46. Guo, S.; Matsukawa, K.; Miyata, T.; Okubo, T.; Kuroda, K.; Shimojima, A. Photoinduced bending of self-assembled azobenzene-siloxane hybrid. J. Am. Chem. Soc. 2015, 137, 15434-15440. [CrossRef] [PubMed]

47. Wang, Y.; Wang, Y.; Gan, Q. Synthesis and luminescence properties of spherical bridged polysilsequioxanes activated by lanthanide ions. J. Sol-Gel Sci. Technol. 2010, 56, 141-144. [CrossRef]

48. Bürglová, K.; Noureddine, A.; Hodačová, J.; Toquer, G.; Cattoën, X.; Wongchiman, M. A general method for preparing bridged organosilanes with pendant functional groups and functional mesoporous organosilicas. Chem. A Eur. J. 2014, 20, 10371-10382. [CrossRef]

49. Cornelius, M.; Hoffmann, F.; Ufer, B.; Behrens, P.; Fröba, M. Systematic extension of the length of the organic conjugated $\pi$-system of mesoporous silica-based organic-inorganic hybrid materials. J. Mater. Chem. 2008, 18, 2587-2592. [CrossRef]

50. Dirè, S.; Tagliazucca, V.; Callone, E.; Quaranta, A. Effect of functional groups on condensation and properties of sol-gel silica nanoparticles prepared by direct synthesis from organoalkoxysilanes. Mater. Chem. Phys. 2011, 126, 909-917. [CrossRef]

51. Blanco, I. The rediscovery of POSS: A molecule rather than a filler. Polymers 2018, 10, 904. [CrossRef]

52. Pan, D.; Yi, E.; Doan, P.H.; Furgal, J.C.; Schwartz, M.; Clark, S.; Goodson, T., III; Laine, R.M. Microporous inorganic/organic hybrids via oxysilylation of a cubic symmetry nanobuilding block $\left[\left(\mathrm{HMe}_{2} \mathrm{SiOSiO}_{1.5}\right)_{8}\right]$ with RxSi(OEt) ${ }_{4-x}$. J. Ceram. Soc. Jpn. 2015, 123, 756-763. [CrossRef]

53. Yang, X.; Yin, G.; Li, Z.; Wu, P.; Jin, X.; Li, Q. The preparation and chemical structure analysis of novel POSS-based porous materials. Materials 2019, 12, 1954. [CrossRef] [PubMed]

54. Xu, X.; Yu, J.; Xue, L.; Zhang, C.; Zha, Y.; Gu, Y. Investigation of molecular structure and thermal properties of thermo-oxidative aged SBS in blends and their relations. Materials 2017, 10, 768. [CrossRef]

55. Bautista, Y.; Gozalbo, A.; Mestre, S.; Sanz, V. Thermal degradation mechanism of a thermostable polyester stabilized with an open-cage oligomeric silsesquioxane. Materials 2017, 11, 22. [CrossRef] 
56. Loy, D.A.; Jamison, G.M.; Baugher, B.M.; Russick, E.M.; Assink, R.A.; Prabakar, S.; Shea, K.J. Alkylene-bridged polysilsesquioxane aerogels: Highly porous hybrid organic-inorganic materials. J. Non.-Cryst. Solids 1995, 186, 44-53. [CrossRef]

57. Feinle, A.; Elsaesser, M.S.; Hüsing, N. Sol-gel synthesis of monolithic materials with hierarchical porosity. Chem. Soc. Rev. 2016, 45, 3377-3399. [CrossRef]

58. Chen, T.; Li, M.; Liu, J. $\pi-\pi$ Stacking Interaction: A nondestructive and facile means in material engineering for bioapplications. Cryst. Growth Des. 2018, 18, 2765-2783. [CrossRef]

59. Ronchi, M.; Sulaiman, S.; Boston, N.R.; Laine, R.M. Fluoride catalyzed rearrangements of polysilsesquioxanes, mixed Me, vinyl $\mathrm{T}_{8}, \mathrm{Me}$, vinyl $\mathrm{T}_{10}$ and $\mathrm{T}_{12}$ cages. Appl. Organomet. Chem. 2009, 24, 551-557. [CrossRef]

60. Krug, D.J.; Asuncion, M.Z.; Laine, R.M. Facile Approach to Recycling Highly Cross-Linked Thermoset Silicone Resins under Ambient Conditions. ACS Omega 2019, 4, 3782-3789. [CrossRef]

(C) 2020 by the authors. Licensee MDPI, Basel, Switzerland. This article is an open access article distributed under the terms and conditions of the Creative Commons Attribution (CC BY) license (http://creativecommons.org/licenses/by/4.0/). 